\title{
Microwave Sintering of Ceramics for Dentistry: Part 1
}

\author{
R Vaderhobli* and S Saha ${ }^{2}$
}

${ }^{1}$ Department of Preventive and Restorative Dentistry, UCSF School of Dentistry, San Francisco, CA 94143, USA

${ }^{2}$ Department of Orthopaedic Surgery and Rehabilitation Medicine, SUNY-Downstate Medical Center, Brooklyn, NY 11203, USA

\begin{abstract}
The objective of this study was to examine the feasibility of sintering dental ceramic (e.g., zirconia) in a microwave oven, and compare the mechanical properties of these with similar materials sintered in a conventional furnace. Zirconia cylinders were heated to $1100^{\circ} \mathrm{C}, 1300^{\circ} \mathrm{C}, 1350^{\circ} \mathrm{C}, 1400$ and $1450^{\circ} \mathrm{C}$ in microwave and conventional furnaces and sintered at varying dwell times. Our results showed that the mechanical and microstructural properties of samples sintered by microwave were comparable to those of the conventionally sintered samples. Indentation hardness and fracture toughness were found to be $1256 \pm 7$ and $6.4 \pm 0.4 \mathrm{Mpa}(\mathrm{m})^{0.5}$ respectively. The microwave samples were sintered in significantly less time had less voids and more uniform grain structure. Our results suggest that microwave sintering can produce rapid and reliable processing of complex dental ceramics with better microstructural properties and energy savings.
\end{abstract}

Keywords: Ceramics; Porcelain; Microwave; Sintering

\section{Introduction}

During microwave sintering, microwaves penetrate the material; some of the energy is absorbed by the material and converted to heat. The formation of heat raises the temperature of the material. However the surface of the material loses more heat to the surroundings than the interior, hence the interior parts of the material become hotter than the exterior [1].

Microwave Hybrid Heating ( $\mathrm{MHH})$ is a process of heating electrically transparent (low-loss) materials like silica, alumina and zirconia [2]. To enable microwave penetration and heating, these samples have to be preheated by another source, which can couple with microwaves at room temperature. The ceramic, silicon carbide is usually used as a susceptor or a pre-heater because it couples well with microwaves at room temperatures unlike other ceramics, e.g. zirconia. Heating is initiated by the coupling of susceptors with the microwave field at room temperature and as the temperature increases the transparent material becomes more susceptible to microwave energy. At a critical temperature, the low loss material becomes more microwave absorbent thus can be heated by microwave.

In recent years, zirconia has become a material of choice for dental restorations [3]. The objective of this study was to demonstrate the feasibility sintering zirconia-using $\mathrm{MHH}$ and to compare the resultant microstructural and mechanical properties with those of the conventionally sintered samples as previous studies with respect to the use of microwaves for dental ceramics are lacking [4].

\section{Materials and Methods}

Powders of zirconia stabilized with $3 \mathrm{~mol} \%$ yttria (TOSOH, Japan) were uniaxially pressed (compacted) into cylinders with a radius of 8.36 $\pm 0.89 \mathrm{~mm}$ and height of $5.33 \pm 0.34 \mathrm{~mm}$ (wt. $0.58 \mathrm{~g}$ ) using a standard Carver hydraulic piston press and commercial tool steel dies at 2000psi. The samples were cold isostatically pressed at $15000 \mathrm{psi}$. Thirty samples were utilized for conventional sintering and thirty four were sintered with microwave. Each sample was weighed, and the lengths and diameters were measured with a micrometer (Mitutoyo, Japan). A Thermolyne 5000 series tube furnace was utilized to conventionally sinter 30 samples. The furnace was heated at approximately $10^{\circ} \mathrm{C}$ per minute to $1450^{\circ} \mathrm{C}$. Six cylinders were sintered at a time. A total of thirty cylinders were sintered to $1450^{\circ} \mathrm{C}$ in this manner utilizing the same ramp rate $\left(10^{\circ} \mathrm{C} /\right.$ minute $)$. An additional lot of pellets measuring 2.5 $\mathrm{mm} \times 0.4 \mathrm{~mm} \times 6 \mathrm{~g}$ were prepared by the above mentioned methods and sintered in Lindberg conventional furnace at approximately $40^{\circ} \mathrm{C}$ per minute in order to study the effect of increased heating rate.

A multi-magnetron $2 \mathrm{~kW}$ commercial research microwave oven having a stainless steel cavity and equipped with dual mode stirrers, a platinum sheated S-type thermocouple and Omega controller was purchased from the Microwave Research and Applications, Inc (Model number BP 210/211) for the microwave sintering experiments. The operating frequency was $2.45 \mathrm{GHz}$. A thermal and a fibrous alumina cylinder containment box were made using fibrous alumina boards 1.5 inch thick. Three Silicon carbide rings $(25 \mathrm{~mm}$ diameter) were used as preheaters or susceptors. These were sandwiched between the reticulated zirconia plates which also acted as the floor upon which the samples rested. Peak sintering temperatures of $1100^{\circ} \mathrm{C}, 1300^{\circ} \mathrm{C}, 1350^{\circ} \mathrm{C}$, $1400^{\circ} \mathrm{C}, 1450^{\circ} \mathrm{C}$, respectively, were used. Two stainless steel pedestals with equally spaced $4 \mathrm{~mm}$ holes drilled perpendicular to the vertical axis were utilized to hold the S-type thermocouple. An $8 \mathrm{~mm}$ hole was drilled horizontally into the side of the cylindrical portion of the thermal containment cylinder to allow measurement of the temperature within the cavity of the thermal containment box. Temperatures were recorded manually every two minutes. The microwave furnace was started at minimal power. The power was then gradually increased as temperatures ramp dictated until sintering temperature was achieved. All sample-sintering cycles were begun at room temperature.

\section{Post-sintering measurments}

Only those sintered cylinders that had a dimensional density of greater than $80 \%$ of theoretical (using $6.06 \mathrm{~g} / \mathrm{cm}^{3}$ for zirconia) were analysed using the Archimedes method. The specimens which were sintered at different temperatures were polished and Vickers hardness and toughness values were measured at 20 and $30 \mathrm{kgs}$.

*Corresponding author: Dr. R. Vaderhobli, 707 Parnassus Avenue, Room D 1028, San Francisco, CA 94143-0758, USA, Tel: 415-476-4469; Fax: 415-4760858; E-mail: ram.vaderhobli@ucsf.edu

Received May 27, 2015; Accepted June 15, 2015; Published June 20, 2015

Citation: Vaderhobli R, Saha S (2015) Microwave Sintering of Ceramics for Dentistry: Part 1. Dentistry 5: 311. doi:10.4172/2161-1122.1000311

Copyright: (c) 2015 Vaderhobli R, et al. This is an open-access article distributed under the terms of the Creative Commons Attribution License, which permits unrestricted use, distribution, and reproduction in any medium, provided the original author and source are credited. 
The samples from both conventional and microwave sintering were thermally etched to $100^{\circ} \mathrm{C}$ less than the sintering temperature and held for 1 to 1.5 hours. The samples were sputter coated with gold palladium for 3 minutes ( 300 angstrom thick coating) and examined by a Scanning Electron Microscope (PHILIPS).

\section{Results}

For conventional sintering, $10^{\circ} \mathrm{C}$ per minute heating rate resulted in a uniform temperature-time profile curve. The sintering temperature of $1450^{\circ} \mathrm{C}$ was reached in approximately two and half hours. The cooling ramp rate was also nearly $10^{\circ} \mathrm{C}$ per minute. This heating profile resulted in dense sintered sample with a translucent sheen indicating that they were fully sintered after a period of six hours. Faster ramp rates (in excess of $40^{\circ} \mathrm{C}$ ) rendered insufficient sintering of samples and these specimens were highly porous.

To reach a peak temperature of $1100^{\circ} \mathrm{C}$ in a $\mathrm{M} / \mathrm{W}$ furnace, we used a ramp rate in excess of $100^{\circ} \mathrm{C} / \mathrm{min}$. However, upon removal of the samples after cooling, they were not completely sintered, and had warped to a certain extent. The low temperature of $1100^{\circ} \mathrm{C}$ with no dwell time was insufficient to sinter the samples and attempts to use dwell times of 20 and 30 minutes resulted in damage to the floor of the microwave oven. The maximum power required to achieve the sintering temperature of $1300^{\circ} \mathrm{C}$ was 78 percent. For samples that were sintered to $1400^{\circ} \mathrm{C}$ and $1450^{\circ} \mathrm{C}$ the power had to be manipulated initially until the temperature rose to about $380^{\circ} \mathrm{C}$. Final power of 72 percent increased the microwave heating to an extent that heating rates of approximately $150^{\circ} \mathrm{C}$ allowed the final temperature of $1400^{\circ} \mathrm{C}$ or $1450^{\circ} \mathrm{C}$ to be achieved as shown in Figure 1. Again, the samples, upon examination were intact with no signs of cracking and had a translucent sheen, which was not observed, at other sintering temperatures. Ramp rates in excess of $150^{\circ} \mathrm{C}$ resulted in damage to the floor of the microwave oven. However, the samples were completely sintered in less than 10 minutes.

At lower microwave sintering temperatures of $1100^{\circ} \mathrm{C}, 1300^{\circ} \mathrm{C}$ and $1350^{\circ} \mathrm{C}$ the density was considerably less than the conventionally sintered samples. There was no significant difference in the density at $1450^{\circ} \mathrm{C}$ for both microwave and conventionally sintered samples as shown in Table 1. The comparison of hardness between the conventionally sintered and the microwave sintered samples at $30 \mathrm{Kg}$ load yielded similar results with the samples sintered with microwaves at $1450^{\circ} \mathrm{C}$ displaying higher hardness values than the conventionally sintered samples at the same temperature. The fracture toughness increased with the sintering temperature as shown in Table 1 and the values for $\mathrm{HV}_{20}$ indentations were comparable with the microwavesintered samples at sintering temperatures $1450^{\circ} \mathrm{C}$ as with those samples sintered conventionally at that temperature. Cracks measured at the center had propagated more than those measured at the edges of the samples. The average microstructure of the microwave-sintered samples had less voids than that of the conventionally sintered samples when examined at the same magnification of $10000 \mathrm{X}$. No significant difference in the grain shape was observed between the two sintering methods. The samples sintered in a conventional furnace with slow ramp rate of $10^{\circ} \mathrm{C}$ per minute had slightly larger grains in the interior than the exterior as shown in Figure 2. The average grain size at the exterior was approximately $0.3 \mu \mathrm{m}$, while at the interior; it was approximately $0.7 \mu \mathrm{m}$. This suggests that the temperature of the external surface might have been higher than the interior. Few voids were also seen in these samples. The microstructure as shown in Figure 3 appeared to be more uniform throughout the sample and few slightly larger grains $(0.5 \mu \mathrm{m})$

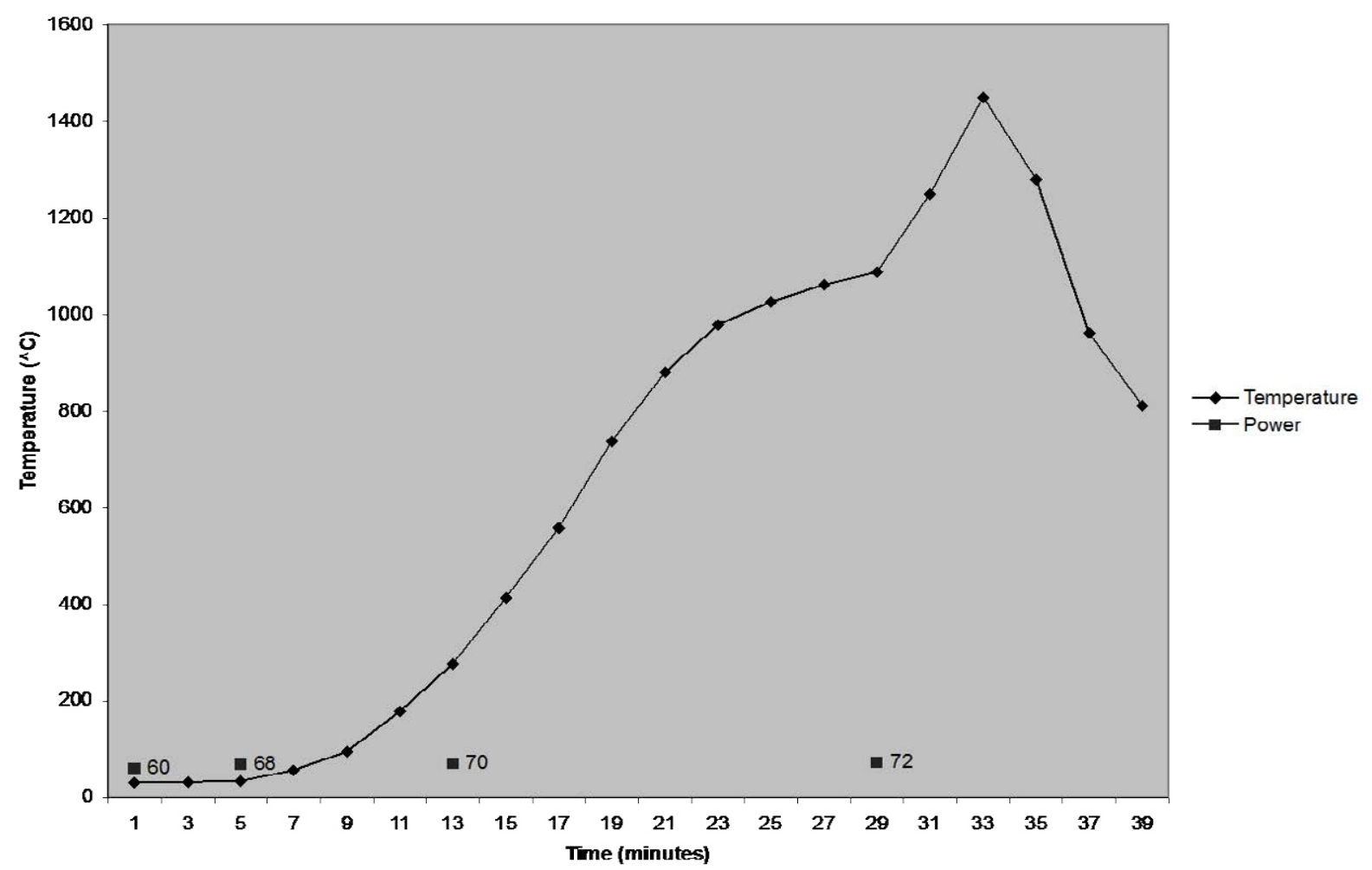

Figure 1: Time vs temperature profile along with microstructres of a zirconia sample sintered in a microwave. The percentage of full power utilized is also shown along with the changes in microstructure. 


\begin{tabular}{|c|c|c|c|c|c|}
\hline Temp $\left({ }^{\circ} \mathrm{C}\right)$ & $\mathrm{VHN}_{20}$ & $\begin{array}{c}\mathrm{Kic}_{20} \text { (Mpa. } \\
\mathbf{m}^{0.5} \text { ) }\end{array}$ & $\mathrm{VHN}_{30}$ & $\begin{array}{c}\mathrm{Kic}_{30} \\
\left(\mathrm{Mpa}_{30} \mathbf{m}^{0.5}\right)\end{array}$ & Densi \\
\hline 11 & 2060.7 & $3.1 \pm 0.2$ & $275 \pm 7.8$ & Inaccurate & $56.3 \pm 3.7$ \\
\hline 1300 & $7 \pm 16$ & $4.8 \pm 0.13$ & $63=$ & 23 & 0. \\
\hline 13 & 417 & \pm 0.4 & 7 & 3 & 2 \\
\hline $1400-\mathrm{m} / \mathrm{w}$ & $1039 \pm 11$ & $5.6 \pm 0.2$ & $1035 \pm 10$ & $6.4 \pm 0.2$ & $96 \pm 0.9$ \\
\hline $1450-\mathrm{m} / \mathrm{w}$ & $1256 \pm 7$ & $6.4 \pm 0.4$ & $1267 \pm 18$ & $6.8 \pm 0.13$ & $98 \pm 0.9$ \\
\hline Convent & $1130 \pm 25$ & $6.5 \pm 1.1$ & $1237 \pm 29$ & $6.6 \pm 0.8$ & $8.04 \pm 2$ \\
\hline
\end{tabular}

Table 1: Mean standard deviation of the Mechanical Property (Vickerns Hardness Numbers (VHN at 20 and $30 \mathrm{kgs}$ ) and respective fracture toughness (Kic at 20 and $30 \mathrm{kgs})$ ) of Zirconia samples sintered in a microwave at various temperatures and in a conventional oven at $1450^{\circ} \mathrm{C}$

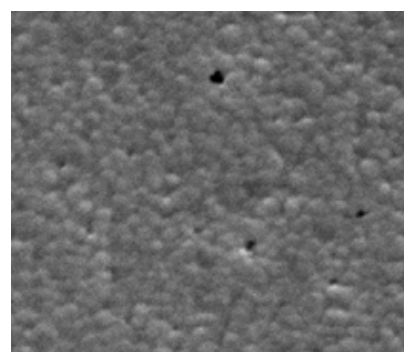

A

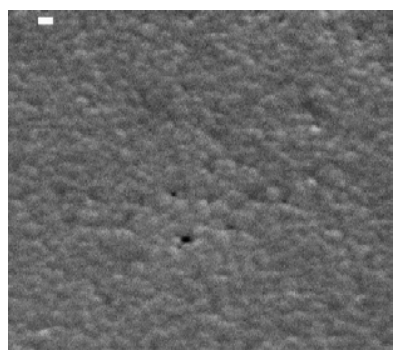

B
Figure 2: SEM micrographs displaying smaller grains in the exterior $(B)$ as compared to the interior $(A)$ of the conventionally sintered samples $\left(1450^{\circ} \mathrm{C}\right.$, 10000X).

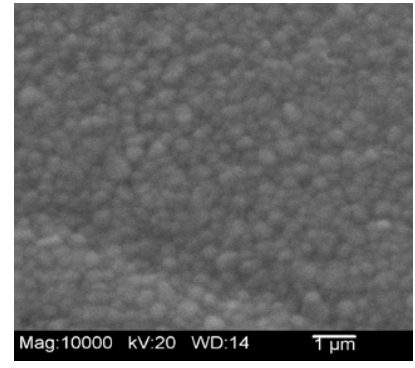

A

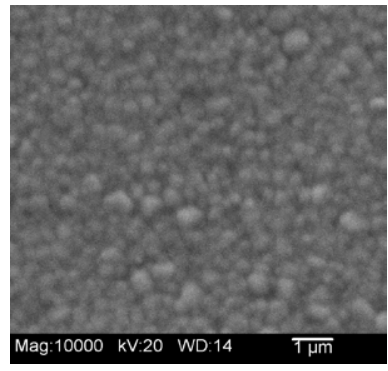

B
Figure 3: SEM micrographs showing uniform grain size distribution for microwave sintered samplesin both exterior $(A)$ and also in the interior $(B)$ due to volumetric heating $\left(1450^{\circ} \mathrm{C}, 10000 \mathrm{X}\right)$.

interspersed with the densely packed smaller grains $(\sim 0.3 \mu \mathrm{m})$ with the average grain size measured to be around $0.3 \mu \mathrm{m}$.

\section{Discussions}

High strength ceramic materials that are inexpensive and durable when subjected to cyclic loading in oral environment and can be made into individually constructed restorations have become available in the market [5]. Such zirconia or alumina blanks for fabricating dental crowns are normally sintered or pre-sintered in a conventional oven. We mimicked the heating and cooling rate employed by a normal dental laboratory for sintering the zirconia blanks in a conventional oven. Conventional sintering with faster ramp rates of about $35^{\circ} \mathrm{C}$ per minute was attempted. However, faster ramp rates rendered insufficient sintering of samples and consequently were highly porous. A possible explanation for the warping may be attributed to uneven temperature distribution for conventional sintering. In contrast, when faster heating rates $\left(40^{\circ} \mathrm{C}\right)$ were applied to the conventional sintering, the samples warped or were distorted due to incomplete sintering. This may be the main reason as to why the dental furnaces for sintering of the ceramic core adhere to slower heating rates. The thermocouple measured the temperature contained within the thermal containment box close to the actual sample and not the actual surface temperature of the samples itself [6-10]. Also, it should be noted that microwave heating is a volumetric heating phenomenon resulting in the interior of the samples being at a higher temperature then the surface [2].

The silicon carbide susceptors (rings) due to their high susceptibility to microwaves at room temperature coupled well with the microwaves and resulted in transformation of this energy to infrared energy which was emitted as heat. Heat began to build up in the containment chamber, which in turn increased the temperature of the ceramic samples. The rate of heating was sufficiently high to achieve high temperatures, which were effective in the coupling of the microwave energy with the zirconia (both the reticulated zirconia and the sample) at the critical couple-triggering temperature. Zirconia, at this point, in a given sintering process, became more susceptible to microwave energy, thereby absorbing energy at a rate greater than that of the silicon carbide susceptors.

This study showed that the most significant factors affecting the density of samples in microwave and conventional heating were the sintering temperatures. Increasing the ramp rate made no significant difference in the density-temperature relationships between conventionally and microwave sintered samples. The conventionally sintered samples with heating rates of $10^{\circ} \mathrm{C}$ per minute compared well with the faster $\left(>90^{\circ} \mathrm{C}\right)$ heating rates of microwave-sintered samples. The hardness values of the microwave samples sintered at $1450^{\circ} \mathrm{C}$ were comparable with that of the published values for conventionally sintered zirconia when used as a dental biomaterial [5].

$\mathrm{HV}_{20}$ indentations were comparable with the microwave-sintered samples at sintering temperatures $1450^{\circ} \mathrm{C}$ as with those samples sintered conventionally at the same temperature. The increase in the standard deviation of the hardness values for conventionally sintered samples may be due to the non-uniformity in the grain size. Because the surface energy for diffusion mechanism is from the exterior to the interior, the grains at the edges were considerably smaller than those at the centers as shown in Figure 2, which absorbed more energy absorption when indented and may have prevented further propagation of the crack. Moreover, the amount of transformed grains, or the size of transformation zone depends upon the transformability of the tetragonal phase, which is controlled mainly by the grain size [11]. Also, the fracture toughness values are influenced by the mode of propagation of the cracks [3]. The indentation fracture toughness values for samples sintered in a microwave oven or in a conventional oven at $1400^{\circ} \mathrm{C}$ were comparable (Table 1 ).

Mechanical properties of a material are not only influenced by its microstructure, but also by the defects present $[12,13]$. The uniform microstructure as shown in Figure 3 was more uniform throughout the sample perhaps due to the volumetric heating by microwave.

\section{Conclusion}

Summarily, transfer of new processing technology from the ceramic industry to dental materials has realized the potential of microwave sintering for dental ceramics. The study suggests that further investigations of the role of the dwell periods at sintering temperatures of $1250-1300^{\circ} \mathrm{C}$ should be conducted. Sintering at lower temperatures would provide more energy savings and may need less furnace time. The purpose of this study was to examine the feasibility of microwave 
ovens in sintering dental ceramics and to develop an ideal microwave sintering profile for firing of crowns and bridges, which could be used in restorative dentistry. The results of this study demonstrate the enormous time savings and other benefits of very rapid sintering. We hope that based on our work new industries related to microwave sintering of dental ceramics would be developed.

\section{Acknowledgements}

We would like to thank Mr. Gary Del Regno for his technical assistance and State University of New York at Alfred University for laboratory support.

\section{References}

1. Goldstein A, Travitzky N, Singurindy A, Kravchik M (1999) Direct Microwave Sintering of Yttria-stabilized Zirconia at $2.45 \mathrm{GHz}$. Journal of The European Ceramic Society 19: 2067-2072.

2. Peng $H$, Tinga WR, Sundararaj U, Eadie RL (2003) Microwave sintering process model. J Microw Power Electromagn Energy 38: 243-258.

3. Francischone CE, D'Alpino PH, Garcia FC, Pereira JC (2003) Reconstruction of anterior teeth using an aesthetic post-and-core and all-ceramic material. Pract Proced Aesthet Dent 15: 459-464.

4. Liang W, D'Alessandro DM (2013) Microwave-assisted solvothermal synthesis of zirconium oxide based metal-organic frameworks. Chem Commun (Camb) 49: $3706-3708$.
5. Sundar V, Kennedy CR (2001) Cercon-Zirconia-A Systems Solutions for Reliable Metal-free Multi-unit Restorations. Quintessence 52: 811-4.

6. Birnboim A, Carmel Y (1999) Simulation of Microwave Sintering of Ceramic Bodies with Complex Geometry. Journal of American Ceramic Society 82: 11.

7. Boch P, Lequeux N (1997) Do Microwaves Increase the Sinterability of Ceramics. Solid State Ionics 101-103: 1229-1233.

8. Casellas D, Feder A, Llanes L, Anglada M (2001) Fracture toughness and mechanical strength of Y-TZP/PSZ ceramics. Scripta Materialia 45: 213-220.

9. Mukhopadhyay AK, Chaudhuri MR (2001) Mechanical Characterization of Microwave Sintered Zinc Oxide. Bulletin of Material Science 24: 125-128.

10. Pert E, Carmel, Y, Birnboim A, Olorunyolemi T, Gershon D, et al. (2001) Temperature Measurements during Microwave Processing: The Significance of Thermocouple Effects. Journal of American Ceramic Society 84: 1981-1986.

11. Sheu TS, Tien TY, Chen IW (1992) Cubic-to-Tetragonal (t') Transformation in Zirconia-Containing Systems. Journal of the American Ceramic Society 75 : 1108-1116.

12. Jannet MA, Kimrey HD (1990) Microstructure Evolution in Microwave Sintered Alumina. Sintering of Advanced Ceramics-Ceramic Transcations. C. A. Handwerker, J. E. Blendall and W. A. Kaysser. Westerville, OH, The American Ceramic Society. 7: 382-390.

13. Quinn JB, Sundar V, Lloyd IK (2003) Influence of microstructure and chemistry on the fracture toughness of dental ceramics. Dent Mater 19: 603-611. 